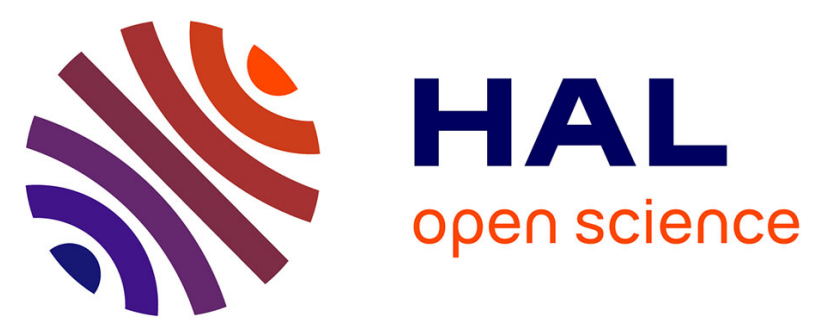

\title{
Six recommendations for improving monitoring of diseases shared with wildlife: examples regarding mycobacterial infections in Spain
}

Mariana Boadella, Christian Gortazar, Pelayo Acevedo, Tania Carta, María Paz Martín-Hernando, José Fuente, Joaquín Vicente

\section{To cite this version:}

Mariana Boadella, Christian Gortazar, Pelayo Acevedo, Tania Carta, María Paz Martín-Hernando, et al.. Six recommendations for improving monitoring of diseases shared with wildlife: examples regarding mycobacterial infections in Spain. European Journal of Wildlife Research, 2011, 57 (4), pp.697-706. 10.1007/s10344-011-0550-x . hal-00701273

\section{HAL Id: hal-00701273 \\ https://hal.science/hal-00701273}

Submitted on 25 May 2012

HAL is a multi-disciplinary open access archive for the deposit and dissemination of scientific research documents, whether they are published or not. The documents may come from teaching and research institutions in France or abroad, or from public or private research centers.
L'archive ouverte pluridisciplinaire HAL, est destinée au dépôt et à la diffusion de documents scientifiques de niveau recherche, publiés ou non, émanant des établissements d'enseignement et de recherche français ou étrangers, des laboratoires publics ou privés. 


\title{
Six recommendations for improving monitoring of diseases shared with wildlife: examples regarding mycobacterial infections in Spain
}

\author{
Mariana Boadella $\cdot$ Christian Gortazar • Pelayo Acevedo • Tania Carta • \\ María Paz Martín-Hernando • José de la Fuente • Joaquín Vicente
}

Received: 19 August 2010/Revised: 8 May 2011 / Accepted: 16 May 2011/Published online: 25 May 2011

(C) Springer-Verlag 2011

\begin{abstract}
Monitoring is needed to identify changes in disease occurrence and to measure the impact of intervention. Using mycobacterial diseases as an example, we discuss herein the pros and cons of the current Spanish Wildlife Disease Surveillance Scheme providing suggestions for monitoring relevant diseases shared with wildlife in other regions facing similar challenges. Six points should be considered. This includes: (1) making sure the disease is properly monitored in the relevant domestic animals or even in humans; (2) also making sure that background information on wildlife population ecology is available to maximize the benefits of the monitoring effort; (3) selecting the appropriate wildlife hosts for monitoring, while being flexible enough to incorporate new ones if research suggests their participation; (4) selecting the appropriate methods for diagnosis and for time and space trend analysis; (5) deciding which parameters to target for monitoring; and finally (6) establishing a reasonable sampling effort and a suitable sampling stratification to
\end{abstract}

Communicated by A. Aguirre

M. Boadella $(\varangle) \cdot$ C. Gortazar $\cdot$ T. Carta $\cdot$

M. P. Martín-Hernando $\cdot$ J. de la Fuente $\cdot$ J. Vicente

Instituto de Investigación en Recursos Cinegéticos,

IREC (CSIC-UCLM-JCCM),

Ronda de Toledo $\mathrm{s} / \mathrm{n}$,

13071, Ciudad Real, Spain

e-mail: mariana.boadella@gmail.com

P. Acevedo

Biogeography, Diversity, and Conservation Research Team, Animal Biology, Department of Sciences, University of Malaga,

29071, Málaga, Spain

J. de la Fuente

Department of Veterinary Pathobiology, Center for Veterinary

Health Sciences, Oklahoma State University,

Stillwater, OK 74078, USA ensure detecting changes over time and changes in response to management actions. Wildlife disease monitoring produces knowledge that benefits at least three different agencies, namely, animal health, public health and conservation, and these should combine efforts and resources. Setting up stable, comprehensive and accurate schemes at different spatial scales should become a priority. Resources are always a limiting factor, but experience shows that combined, cross-collaborative efforts allow establishing acceptable schemes with a low enough cost to be sustainable over time. These six steps for monitoring relevant shared diseases can be adapted to many other geographical settings and different disease situations.

Keywords Disease monitoring · Paratuberculosis · Time trends $\cdot$ Tuberculosis $\cdot$ Wildlife diseases $\cdot$ Zoonoses

\section{Introduction}

The history of wildlife disease surveillance in Europe possibly started with the first passive surveillance schemes set up in Scandinavian countries in the 1930s (Mörner et al. 2002). Surveillance of rabies (King et al. 2004) and trichinellosis (Blancou 2001) started afterwards. However, the first scientific meetings did not occur until the early 1990s (Symposium on the health and management of freeranging mammals held in Nancy, France, in 1991; First conference of the European section of the Wildlife Disease Association EWDA, in Paris, France, in 1994). These meetings prompted a more widespread interest in wildlife disease surveillance. In the last decades, classical swine fever in Eurasian wild boar (Sus scrofa; Rossi et al. 2005) and highly pathogenic avian influenza (Chen et al. 2005) further contributed to a growing interest on diseases shared 
with wildlife such as zoonotic diseases and diseases that have potential risk for domestic species (Gortazar et al. 2007). Detection of these relevant diseases in wildlife was identified as a determinant of the structure and function of European surveillance schemes (Leighton 1995). At a worldwide scale, the World Organization for Animal Health or OIE working group on wildlife diseases was also established in 1994. It is now recognized that those countries which conduct disease surveillance of their wild animal populations are more likely to detect the presence of infectious and zoonotic diseases and to swiftly adopt counter measures (Mörner et al. 2002).

In Spain, the interest in wildlife diseases started in the 1980s and was boosted in 1989 with the emergence of rabbit hemorrhagic disease in European wild rabbits (Oryctolagus cuniculus; Villafuerte et al. 1994). In the last decade, however, resources for studying wildlife diseases increased after the identification of wildlife species as actors in the epidemiology of important livestock diseases, such as Aujeszky's disease (Müller et al. 1998), bluetongue (Ruiz-Fons et al. 2008) and bovine tuberculosis (bTB; Naranjo et al. 2008), and more recently after realizing the importance of diseases in Iberian lynx (Lynx pardinus) conservation (Millán et al. 2009). Risk factors for the appearance of wildlife reservoirs are commonly the spillover from domestic livestock in combination with anthropogenic activities such as translocation of wildlife, supplemental feeding of wildlife and wildlife populations reaching densities beyond normal habitat carrying capacities (Gortazar et al. 2006; Palmer 2007). This, along with the size of the Spanish livestock industry and the significant proportion of free range breeding systems, prompted specific calls for wildlife disease research in the national grant scheme in 2006 and 2008 (INIA-FAU, http://sp.inia. es/ucc/contenidos/memo1.pdf).

Using mycobacterial diseases as an example, we discuss herein the pros and cons of the current Spanish Wildlife Disease Surveillance Scheme (http://rasve.mapa.es/Publica/ Programas/NORMATIVA\%20Y\%20PROGRAMAS\% 5CPROGRAMAS \% 5 CFAUNA\%20SILVESTRE\% 5CPLAN\%20NACIONAL\%20DE\%20VIGILANCIA\% 20SANITARIA\%20EN\%20FAUNA\%20SILVESTRE_2011. $\mathrm{PDF}$ ), providing suggestions for wildlife disease monitoring in other regions facing similar challenges.

\section{Mycobacterial diseases in European wildlife}

TB in Eurasian badgers (Meles meles) was first diagnosed in Switzerland (Bouvier 1963), a country where no further reports on wildlife TB exist in the scientific literature (Wyss et al. 2000). Later, Mycobacterium bovis was isolated from badgers in southwest England in 1971 and
Ireland in 1973. Since then, the infection in badgers has been found throughout dense badger populations of southwestern England and parts of Wales (Krebs 1997) and throughout Ireland (Dolan 1993). By contrast, there was no published TB case in badgers from the continent since the first description in Switzerland in the 1960s, until a recent case report from Spain (Sobrino et al. 2008). This is surprising, since many countries in continental Europe have both TB and badgers. Lower badger densities as compared to Britain and Ireland may partly explain this absence. However, a lack of targeted surveillance could also contribute (Artois et al. 2009).

More recently, a growing body of evidence suggests that other wildlife hosts do also act as $M$. bovis reservoirs in different parts of Europe (Gortazar et al. accepted for publication), including the Eurasian wild boar in Spain (Naranjo et al. 2008) and Portugal (Santos et al. 2009) and several cervids in different countries (e.g., Gortazar et al. 2008). As many countries attempt to eradicate bTB from domestic livestock, success is impeded by spillback from wildlife reservoirs. It will not be possible to eradicate $M$. bovis from livestock until transmission between wildlife and domestic animals is halted. Such an endeavor will require a collaborative effort between agricultural, wildlife, environmental and political interests (Palmer 2007). Nowadays, TB is among the wildlife diseases receiving more attention by scientists and government agencies.

Paratuberculosis in wildlife, by contrast, is receiving far less attention in wildlife than TB. This disease, caused by Mycobacterium avium paratuberculosis (MAP), has been considered as a major disease of ruminants for more than a century and has significant economic and welfare effects on livestock in all continents. Recently, this bacterium has received an increasing interest because of scientific evidence that suggest that human infection with this microorganism may be causing some, and possibly all, cases of Crohn's disease (Naser et al. 2004; Uzoigwe et al. 2007). The incidence of paratuberculosis is high in animals kept intensively under environmental and husbandry conditions which are conducive to the spread of the infection (Chiodini et al. 1984). Cervids and other wild ruminants have frequently been identified as MAP hosts, and high prevalence along with clinical disease was reported in some cases (Balseiro et al. 2008), but not in others (Carta et al. in press). In Scotland, wild rabbits have been identified as true wildlife MAP reservoirs too (Beard et al. 2001), and a similar status may locally apply in Spain (Maio et al. in press).

However, regular surveillance, other than the annual reporting of $\mathrm{TB}$ cases and far more sporadic reporting of wildlife paratuberculosis to the OIE, is not done at the (European) country level, or at least not recorded in the scientific literature. 


\section{Wildlife disease monitoring}

Wildlife disease monitoring can be defined as the systematic recording of epidemiological data, with the specific purpose of detecting spatial and temporal trends as well as the presence/absence of the disease. Data and samples gathered can be used for detecting emerging diseases (Rhyan and Spraker 2010) and in retrospective studies (Oleaga et al. 2008; Ruiz-Fons et al. 2008). Ideally, monitoring information should integrate data on the risk factors determining the pathogen epidemiology, such as host abundance and distribution, as they can inform us on potential disease spread in a given spatial or temporal frame. The concept is similar to surveillance, which is done in order to meet the objectives of controlling the disease (Artois et al. 2009). In contrast to disease surveillance, which may be passive based on clinical cases or active based on random sampling, monitoring is more often active.

Disease control at the human-livestock-wildlife interface should be based on a thorough knowledge of the "natural history" (ecology) of the disease agent and its human, domestic and wild hosts (Woodford 2009). Disease and population monitoring is a fundamental part of disease ecology. Figure 1 presents a diagram of how new diseases usually lead first to descriptive epidemiology and eventually to risk factor analyses and control actions. If humans or domestic animals are affected, disease monitoring will start early in time. The decision to monitor this disease in wildlife will depend on the relevance of wildlife hosts as disease reservoirs for humans or domestic animals or on the effects of the disease on wildlife population dynamics. Only if at least one of these options is suspected will monitoring of the disease among wildlife hosts be considered. As a consequence, wildlife disease monitoring usually starts much later in time. However, while this is the case for most regions in developed countries, in areas where wildlife species provide greater economic returns than livestock, the opposite might be the case. This has driven wildlife research and monitoring schemes in less developed countries where livestock and human health care are poor or nonexistent (Kock et al. 2002).

Disease monitoring in wildlife is promoted in order to obtain information to compare with the distribution and prevalence trends in livestock, as a basis for decision making regarding wildlife disease control, and as a means for assessing the effects of any disease management action. Monitoring, by definition, has no limited time frame. Monitoring wildlife disease trends requires adequate diagnostic methods and differential diagnoses; a large-scale and long-term sampling network; the logistics linked to the preparation, distribution and conservation of valuable wildlife samples; and expertise for data management and analysis. In addition, a vital need exists to gather data from the ecology and wildlife management field in order to combine them with disease information regarding both wildlife and livestock (Delahay et al. 2009).

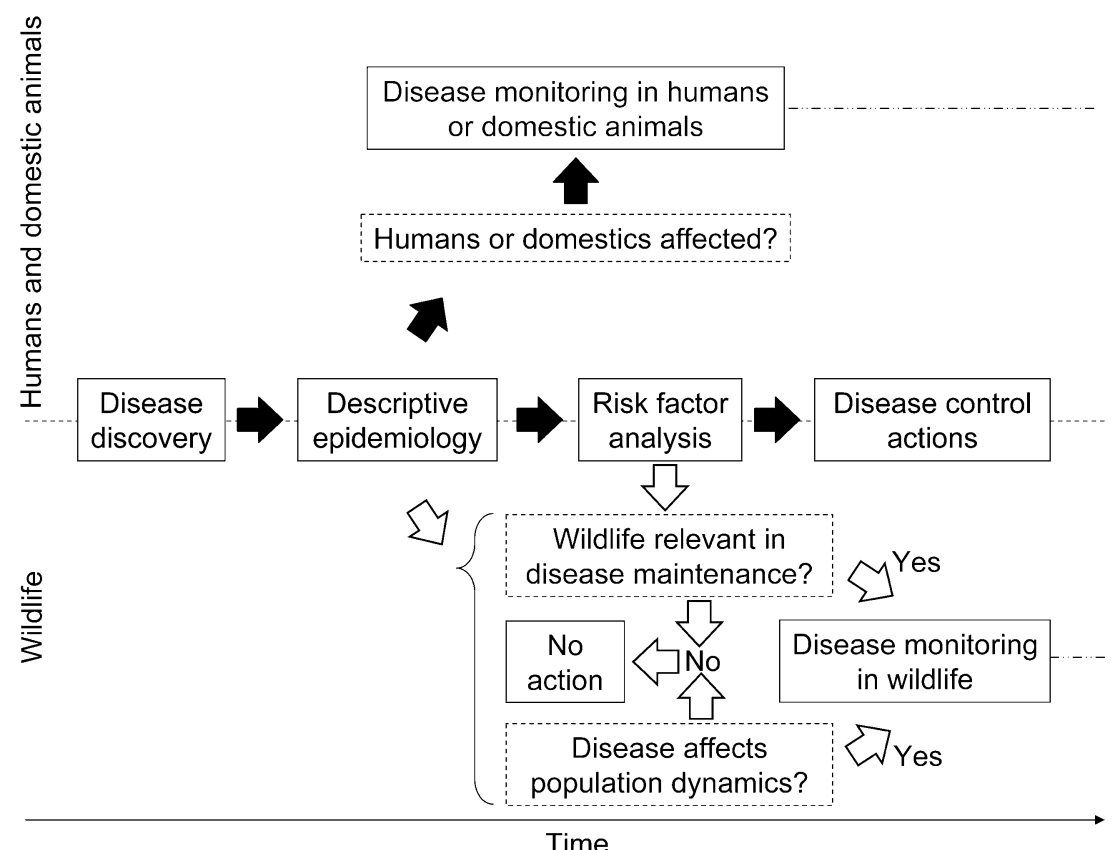

Fig. 1 Schematic representation of disease management in humans and domestic animals (upper part) and wildlife (lower part). Dotted boxes indicate decisions and the arrow at the bottom suggests time. Wildlife disease monitoring will mainly occur if wildlife species are identified as significant reservoirs for humans or domestic animals, or if the disease has a significant impact on wildlife populations. This will probably happen later in time than monitoring in humans or domestics 


\section{Recommendations for monitoring diseases in wildlife}

To properly monitor a wildlife disease, several points must be considered. This includes: (1) making sure the disease, if shared, is properly monitored in the relevant domestic animals or even in humans; (2) also making sure that background information on wildlife population ecology is available to maximize the benefits of the monitoring effort; (3) selecting the appropriate wildlife hosts for monitoring, while being flexible enough to incorporate new ones if research suggests their participation; (4) selecting the appropriate methods for diagnosis and for time/space trend analysis; (5) deciding which parameters to target for monitoring: one or more disease agents, or lesions or contact as revealed by serum antibodies; and finally (6) establishing a reasonable sampling effort and a suitable sampling stratification that can be prolonged over time.

First, if the disease is shared with humans or domestic animals, do appropriate monitoring programs that allow, for instance, trend comparisons between these and wildlife exist? Regarding bTB, good information on the prevalence and incidence in bovine livestock will be available in most European situations. But, at the same time, information may be lacking for other relevant - or potentially relevant domestic species such as goats and free-range pigs.

Second, wildlife disease monitoring will only make sense if population monitoring is carried out at the same time, allowing to link changes in abundance or management with changes in disease indicators (Acevedo et al. 2007). This should include not only the target wildlife hosts but also other relevant competitor or prey species (Sobrino et al. 2009).

Third, wildlife disease monitoring should select for the most appropriate wildlife hosts, considering not only distribution, abundance, degree of protection, prevalence and disease susceptibility but also ease of sample collection and diagnostic sensitivity and specificity. For instance, in Spain, TB has mainly been recorded in wild boar, red deer (Cervus elaphus) and fallow deer (Dama dama; e.g., Gortazar et al. 2008), and as previously stated, sporadically in badgers (Sobrino et al. 2008). TB has also occasionally been described in red fox (Vulpes vulpes; Martín-Atance et al. 2005) and Iberian lynx (L. pardinus; Peña et al. 2006). However, wild boar are considered the best TB surveillance target because of their wider distribution, higher abundance and high availability as a game species and because of their lesion distribution (Martín-Hernando et al. 2007). The recent design of a specific and sensitive enough enzymelinked immunosorbert assay (ELISA) test (Aurtenetxe et al. 2008; Boadella et al. 2011) makes sample harvesting and laboratory analyses relatively easy even if only head lymph nodes and blood samples are available. By contrast, the detection of TB-compatible lesions in cervids requires the inspection of the head and neck, thorax and abdomen
(Vicente et al. 2006; Martín-Hernando et al. 2010). Moreover, wild ruminants are often infected with other mycobacteria, such as MAP, further compromising diagnostic specificity of some tests, particularly those based on serum antibodies (Reyes-García et al. 2008; Carta et al. in press). In turn, badgers have a more limited distribution in Spain and are protected by law, making sampling difficult. However, monitoring schemes should be flexible enough to allow incorporating new species if research suggests their participation in disease epidemiology (Delahay et al. 2001).

Fourth, the diagnostic and statistic methods should be defined in a way that assures repeatability and data quality. Diagnostic methods selected for wildlife disease monitoring will depend on factors such as the selected host species and expected sample size, the cost of each test, and its specificity and sensitivity. Tests suitable for their use in wildlife are not always available, and the difficulties imposed by field sampling contribute to reduce test sensitivity (Donnelly and Hone 2010). Statistical methods will depend on factors such as the expected prevalence, the geographic scale, the length of the time series and the degree of change in time of the measured variable, being it prevalence or lesion intensity (Joly et al. 2009). It is often of use to study the age-specific prevalence rates, particularly using juvenile prevalence as a proxy for incidence (Wobeser 1994). Epidemiological data are peculiar from a statistical perspective. Data with aggregated distributions are usual in the epidemiological databases, so parametric statistics, which are requiring normal distribution of the data, cannot be generally used (e.g., Jewell 2009). So in risk factor and disease trend assessment, generalized models - with Poisson, negative binomial, zero-inflated or binomial distributions - are needed. Information is often generated at different spatial scales - from individual to population or even to region - and so it is required to use mixed models in which, by means of random variables, pseudoreplication can be avoided (Zuur et al. 2009). Another essential peculiarity is that the epidemiological data of different host species is rarely available at the same spatial resolution and at a high enough resolution to allow meaningful inferences to be made. In general terms, data analyzed should be referred to the same territorial units (municipalities or provinces, for example), and the lowest resolution will determine the spatial resolution of the analysis (see Pfeiffer et al. 2008).

Fifth, once the host species are defined, it must be decided what to target for monitoring. This means defining the agent or agents: $M$. bovis only, or members of the $M$. tuberculosis complex (MTBC), or MTBC and MAP, for instance; and also defining what data will be needed, be it the antigen by culture or PCR, specific antibodies or even characteristic lesions (Vicente et al. 2006; Aurtenetxe et al. 2008; Santos et al. 2010). It is important to choose 
parameters for which detection tools of known effectiveness are available (Wobeser 1994). In addition, it is important to consider testing expenses and budget limitations. Thus, if funding is limited, it can be wise to combine more expensive techniques, such as culture, applied for confirmation to a subsample, with cheaper techniques such as gross pathology (e.g., Vicente et al. 2006). In most cases of mycobacterial disease monitoring, the target will be MTBC, but under certain circumstances, monitoring may need to include MAP because of the relevance of crossreactivity to the tests used or because of the importance of MAP for the regional livestock industry (e.g., Balseiro et al. 2008). Moreover, prevalence rates have a limited value for monitoring chronic diseases with a very protracted course (Wobeser 1994) such as mycobacterial infections.

Finally, it is of paramount importance to define an adequate and reasonable sample size as well as number and distribution of sampling localities according to statistical recommendations (Table 1). We must keep in mind the budget and the current and future logistic constraints such as the laboratory analysis throughput per day, the space available for short- and long-term sample storage and the design of proper databases and sample banking registers. Moreover, sampling must be adequately stratified by age and sex (Vicente et al. 2006), management (Vicente et al. 2007) and study zone (Muñoz et al. 2010). Epidemiology software can help identify suitable sample sizes and can detect time trends when a known initial prevalence and an expected prevalence change are given (e.g., Win Episcope, http://www.clive.ed.ac.uk/cliveCatalogueItem.asp? id=B6BC9009-C10F-4393-A22D-48F436516AC4; European Food Safety Authority 2010). For instance, sampling requirements will depend on the expected initial prevalence or the expected degree of change in these prevalences from time 1 to time 2 (Table 1). In order to spare costs, it may be advisable to pool samples for analysis (e.g., Tayce et al. 2008) or to accumulate samples gathered during several years until the required sample size is achieved (see Table 2).

Table 1 Sample effort needed for the detection of disease according to the expected prevalence (assuming a population size of $>10,000$ ) and for the detection of prevalence variations over $50 \%$ according to the initial prevalence (with a power of $90 \%$ and confidence level of 95\%, Win Episcope 2.0)

\begin{tabular}{|c|c|c|c|c|}
\hline \multirow[b]{2}{*}{ Expected prevalence } & \multicolumn{4}{|c|}{ Detection $P>10,000$} \\
\hline & $0.1 \%$ & $1 \%$ & $5 \%$ & $10 \%$ \\
\hline \multirow[t]{2}{*}{ Required sample size } & 2,990 & 300 & 59 & 29 \\
\hline & \multicolumn{4}{|c|}{ Variation $>50 \%$} \\
\hline Initial prevalence & $1 \%$ & $12 \%$ & $30 \%$ & $60 \%$ \\
\hline Required sample size & 5,098 & 387 & 130 & 44 \\
\hline
\end{tabular}

Monitoring mycobacterial diseases in Spanish wildlife

Spain is a $504,782 \mathrm{~km}^{2}$ country in southwestern Europe that includes two archipelagos, the Canary Islands off the West African coast, the Balearic Islands in the Mediterranean, and the autonomous towns of Ceuta and Melilla in the north of Africa. Based on habitat and climate features and wildlife population characteristics, Spain can roughly be divided into six bioregions (Muñoz et al. 2010; Fig. 2). The compulsory control of bTB in Spanish cattle has been successful, so that current individual cattle incidence is below $0.5 \%$. However, the distribution of positive cattle herds is not uniform, with higher prevalence in Mediterranean habitats of the south and west of the Spanish mainland. Islands with no potential wildlife reservoirs are almost bTB-free (http://rasve.mapa.es/Publica/Programas/ NORMATIVA\%20Y\%20PROGRAMAS/PROGRAMAS/ 2010/TUBERCULOSIS/PROGRAMA\%20NACIONAL\% 20DE\%20ERRADICACION\%20DE\%20TUBERCULOSIS \%20BOVINA.\%20A\%C3\%910\%202010.PDF). Of the susceptible domestic hosts, bTB is only monitored in cattle and in goats living in close contact to cattle. Some regions have also implemented compulsory or voluntary bTB control programs in goats. In Spain, paratuberculosis has been diagnosed for over 20 years in all three (cattle, sheep and goat) domestic ruminant species (Aller et al. 1973; Garrido and León-Vizcaíno 1979), but is not monitored.

The current situation regarding tuberculosis in Spanish wildlife was recently reviewed (Gortazar et al. in press). Paratuberculosis, in turn, has been recorded in farmed red deer (Fernández-de-Mera et al. 2009), but preliminary data from nationwide surveys suggest that wildlife is only locally relevant in MAP epidemiology (Carta et al. in press). This is the case of fallow deer in an intensively grazed mountain area in northern Spain (Balseiro et al. 2008) and possibly of European wild rabbits sharing pastures with infected domestic ruminants in southern Spain (Maio et al. in press). Sporadic records of MAP are also available for wild boar (Álvarez et al. 2005).

Therefore, wildlife TB prevalence is two orders of magnitude higher than in cattle, and it is most likely that certain wildlife reservoirs might locally interfere with the cattle bTB eradication efforts (Gortazar et al. 2008). In addition, TB has killed several endangered Iberian lynxes causing conservation concerns (Peña et al. 2006). These are clear reasons for targeting wild ungulates for TB monitoring and for taking into account the possible interference of MAP in certain diagnostic tools and host species (Boadella et al. 2011; Carta et al. in press). Table 3 presents an overview of the application of the six abovementioned recommendations to the current Spanish circumstances. 
Table 2 Example regarding the Spanish Wildlife Disease Surveillance Scheme

\begin{tabular}{lcccccccc}
\hline & Birds & Carnivores & Hares & Rodents & Wild boar & Red deer & Roe deer & Wild bovids \\
\hline BR 1 & 200 & 60 & 0 & 100 & 400 & 70 & 50 & 20 \\
BR 2 & 100 & 60 & 120 & 200 & 570 & 190 & 60 & 40 \\
BR 3 & 100 & 60 & 90 & 100 & 510 & 250 & 35 & 30 \\
BR 4 & 100 & 60 & 60 & 100 & 245 & 120 & 40 & 60 \\
BR 5 & 200 & 60 & 65 & 0 & 345 & 50 & 20 & 75 \\
BR 6 & 100 & & & 0 & & & & 205 \\
TOTAL & 800 & 300 & 335 & 500 & 2070 & 680 & 225 \\
\hline
\end{tabular}

Probability of detection: Annual samples by taxon and bioregion (BR 1-6). Shadings indicate that sampling is sufficient for the detection of prevalences of $10 \%$ (light grey), 5\% (medium grey), and 1\% (dark grey), with a power of $90 \%$ and confidence level of $95 \%$; Win Episcope 2.0 . White boxes represent situations where these levels are not achieved in only 1 year of sampling

\section{Discussion}

As our knowledge on wildlife diseases grows, disease control becomes more often an option. However, monitoring is needed to identify changes in disease occurrence and to measure the impact of interventions (McDonald et al. 2008). Despite this fact, wildlife disease monitoring is largely in its infancy (Artois et al. 2009), and setting up stable, comprehensive and accurate schemes at different spatial scales (local, national and global) should become a priority for health authorities and wildlife managers.
In many countries including New Zealand, the United States and several ones in the European Union, wildlife vaccination as a means to contribute to bTB control in livestock is being seriously considered (e.g., Tompkins et al. 2009; Chambers et al. 2011; Corner et al. 2009; Ballesteros et al. 2009). In this context, the implementation of wildlife TB-monitoring schemes is a real need.

One point to consider is who takes charge of the monitoring costs. Wildlife disease monitoring produces knowledge that benefits at least three different agencies, namely, animal health, public health and conservation. It

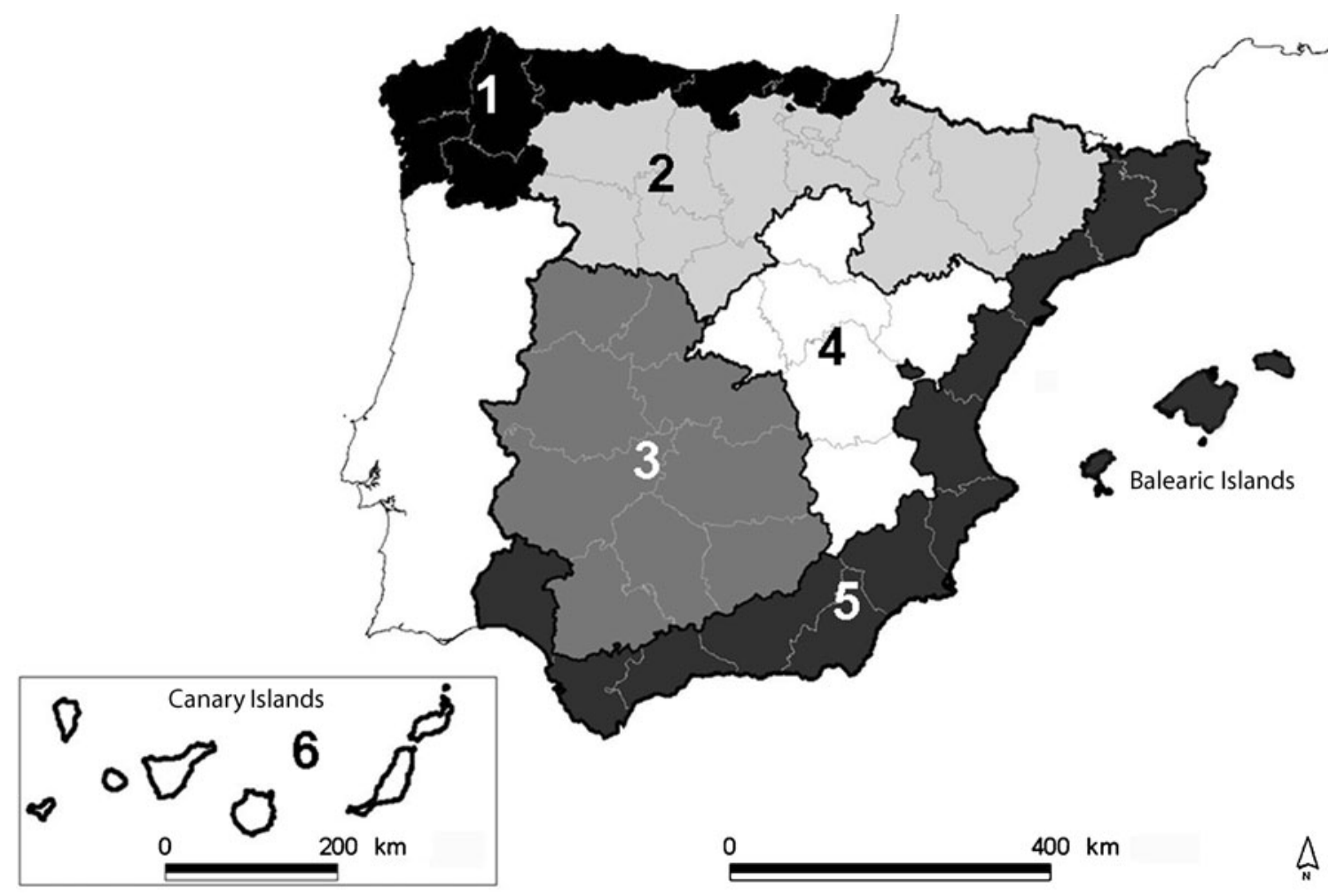

Fig. 2 Map of Spain, with a division into six large bioregions for sampling and wildlife disease monitoring, according to the Spanish Wildlife Disease Surveillance Scheme 
Table 3 Main requisites, current circumstances, and recommendations for TB monitoring in Spanish wildlife

Requisite Current circumstances Recommendations

(1) Disease is properly monitored in the relevant domestic animals or even in humans.

(2) Background information on wildlife population ecology is available to maximize the benefits of the monitoring effort.

(3) Select the appropriate wildlife hosts for monitoring, while being flexible enough to incorporate new ones.

(4) Select appropriate methods for diagnosis and for time trend analysis.

(5) Decide which parameters to target for monitoring: one or more disease agents, or lesions, or contact as revealed by serum antibodies?
Excellent monitoring in cattle.

Include most goat herds in monitoring.

No nationwide compulsory monitoring in other Improve information exchange with medics. domestic animals.

Human cases not always differentiated from $M$. tuberculosis.

Tools for estimating relative abundance and spatial aggregation are available for wild boar (Acevedo et al. 2007). No easy density estimation methods are available for wild boar.

In deer, population density can be estimated (Acevedo et al. 2008, 2010).

Management-related risk factors (feeding, waterholes, fencing) have been identified (Vicente et al. 2007) and are monitored.

Wild boar is an accessible and widespread game Use wild boar as key indicator species. species and is more able to cross fences and likely to contact cattle than other ungulates; serosurveillance already exists for other infections.

Deer are not as widespread.

Badger distribution and abundance is limited.

Foxes are poor sentinels for mycobacterial diseases (Carta et al. 2011; Sobrino et al. 2011). Sensitive and highly specific ELISA available for wild boar (Aurtenetxe et al. 2008; Boadella et al. 2011), lesions easily detectable in wild boar heads (Martín-Hernando et al. 2007).

Cross-reactions and low sensitivity limit the use of ELISA in deer, and TB monitoring in deer requires inspecting whole carcass and using expensive and time-demanding pathology and culture (Martín-Hernando et al. 2010).

Serum antibodies and TB-compatible lesions are time- and cost-effective in wild boar (Vicente et al. 2006; Aurtenetxe et al. 2008; Santos et al. 2010; Boadella et al. 2011).
Decide a tool (dung counts and/or hunting yields) and apply to all selected sampling sites.

Characterize other risk factors and monitor their changes through time.

Collect head lymph nodes and sera, along with data on sex and age.

Where available, use red deer, fallow deer and badger too.

Use ELISA for calculating serum antibody prevalence, pathology for additional lesion scoring, and culture a subsample, for confirmation and molecular epidemiology.

Expertise required for data management and statistical analysis.

Use wild boar serum antibody prevalence as main parameter, lesion scoring as additional tool.

Pay attention to prevalence in juvenile age classes. Some proportion of culture confirmation is advisable for strain characterization and epidemiology.

Stratify sampling by bioregion and cattle bTB prevalence. Better sample from permanent sampling sites, which can be monitored for host abundance and management.
(6) Establish a reasonable sampling effort and distribution.
Wildlife sampling bioregions have been defined and distribution is well described.

Sampling effort depends on regional wild boar abundance and the collaboration of hunters and local authorities. would be wise to combine efforts and resources from all three compartments and to take advantage of the expertise of government agencies and academic institutions. Government attitudes toward wildlife disease research have changed during the last decades for reasons already listed in the "Introduction." Now it is needed to convince other stakeholders too, such as the livestock industry, the hunting lobby or the conservationists, and even medics of the need to monitor wildlife diseases if we are thinking about their future control. Successful examples of collaboration between conservationists and vets [e.g., the detection and management of feline leukemia in the endangered Iberian lynx (López et al. 2009)], between 
vets and medics regarding many zoonoses such as trichinellosis (e.g., Wacker et al. 1999); and between conservationists, medics and vets [e.g., in zoonoses where wildlife are both reservoirs and victims, such as TB (Gortazar et al. 2005, 2008)] should serve as a trigger for future collaborations.

The six steps for surveillance of relevant shared diseases can be adapted to many other geographical settings and different disease situations. Regarding mycobacterial diseases, these are worldwide distributed and do frequently affect multihost systems at the domestic animal-wildlife interface as described for Spain. In any such situation, similar requisites to those outlined in Table 2 do apply. The same requisites are also valid for other disease systems, if they affect domestic animals or humans. For instance, deer might be better indicators of bluetongue virus circulation than vaccinated domestic sheep or cattle (RodríguezSánchez et al. 2010).

Wildlife disease-monitoring programs that are integrated within national animal health surveillance infrastructures should have the capacity to respond promptly to the detection of unusual wildlife mortality and to institute epizootiological researches into new and emerging wildlife diseases (Mörner et al. 2002). Increased training and preparedness of human and animal health staff and government agencies, improved communication and continued research will enhance wildlife-monitoring efforts (Belant and Deese 2010). Resources are always a limiting factor, but the developments toward the monitoring of TB in Spanish wildlife show that combined efforts of local and national government agencies, along with the commitment of trans-disciplinary research, can allow setting up acceptable schemes with a low enough cost to be sustainable in time. Improvements, such as extending animal TB surveillance to goats and pigs and establishing improved links and data exchange with the human health system, are still needed. There exist opportunities for similar approaches elsewhere regarding other diseases, hosts, and geographic circumstances.

Acknowledgments This is a contribution to MCINN Plan Nacional I+D+i research grant AGL2008-03875 and FEDER and to TB-STEP EU grant 212414. Studies on diseases shared between domestic animals and wildlife are also supported by Grupo Santander Fundación Marcelino Botín. Tania Carta acknowledges a grant from Regione Sardegna, and Pelayo Acevedo and Maria Paz MartínHernando acknowledge a Juan de la Cierva (Fondo Social Europeo) and an ISCIII postdoctoral contract from MCINN, respectively. Jose Luis Sáez made valuable comments to the first draft.

\section{References}

Acevedo P, Vicente J, Hofle U, Cassinello J, Ruiz-Fons F, Gortazar C (2007) Estimation of European wild boar relative abundance and aggregation: a novel method in epidemiological risk assessment. Epidemiol Infect 135:519-527
Acevedo P, Ruiz-Fons F, Vicente J, Reyes-Garcia AR, Alzaga V, Gortazar C (2008) Estimating red deer abundance in a wide range of management situations in Mediterranean habitats. J Zool 276:37-47

Acevedo P, Ferreres J, Jaroso R, Durán M, Escudero MA, Marco J et al (2010) Estimating roe deer abundance from pellet group counts in Spain: An assessment of methods suitable for Mediterranean woodlands. Ecol Indic 10:1226-1230

Aller B, Fernández-Díez M, Escudero-Díez A (1973) Paratuberculosis ovina. Supl Científico Bol Inf CGCVE 196:11-18

Álvarez J, De Juan L, Briones V, Romero B, Aranaz A, FernándezGarayzábal JF et al (2005) Mycobacterium avium subspecies paratuberculosis in fallow deer and wild boar in Spain. Vet Rec 156:212-213

Artois M, Bengis R, Delahay R, Duchêne M, Duff P, Ferroglio E et al (2009) Wildlife disease surveillance and monitoring. In: Delahay R, Smith G, Hutchings M (eds) Management of disease in wild mammals. Springer, New York

Aurtenetxe O, Barral M, Vicente J, de la Fuente J, Gortazar C, Juste RA (2008) Development and validation of an enzyme-linked immunosorbent assay for antibodies against Mycobacterium bovis in European wild boar. BMC Vet Res 4:43

Ballesteros C, Garrido JM, Vicente J, Romero B, Galindo RC, Minguijón E et al (2009) First data on Eurasian wild boar response to oral immunization with BCG and challenge with a Mycobacterium bovis field strain. Vaccine 27:6662-6668

Balseiro A, García Marín JF, Solano P, Garrido JM, Prieto JM (2008) Histopathological classification of lesions observed in natural cases of paratuberculosis in free-ranging fallow deer (Dama dama). J Comp Pathol 138:180-188

Beard PM, Rhind SM, Buxton D, Daniels MJ, Henderson D, Pirie A et al (2001) Natural paratuberculosis infection in rabbits in Scotland. J Comp Pathol 124:290-299

Belant JL, Deese AR (2010) Importance of wildlife disease surveillance. Human-Wildlife. Interactions 4:165-169

Blancou J (2001) History of trichinellosis surveillance. Parasite 8:16-19

Boadella M, Lyashchenko K, Greenwald R, Esfandiari J, Jaroso R et al (2011) Serological tests for detecting antibodies against Mycobacterium bovis and Mycobacterium avium subspecies paratuberculosis in Eurasian wild boar. J Vet Diagn Invest 23:77-83

Bouvier G (1963) Transmission possible de la Tuberculose et de la Brucellose du gibier a l'home et aux animaux domestiques et sauvages. Bull LOffice Int Epizooties 59:433-436

Carta T, Aurtenetxe O, Sobrino R, Mamian L, Gerrikagoitia X, Balseiro A et al (2011) Erratum to: lack of evidence of paratuberculosis in wild canids from south-western Europe. Eur J Wildl Res 57(3):695

Carta T, Martin-Hernando MP, Boadella M, Fernández-de-Mera IG, Balseiro A, Sevilla IA et al (in press) Wild red deer are not a Mycobacterium avium paratuberculosis reservoir in the Iberian Peninsula. Vet $\mathrm{J}$

Chambers MA, Rogers F, Delahay RJ, Lesellier S, Ashford R et al (2011) Bacillus Calmette-Guérin vaccination reduces the severity and progression of tuberculosis in badgers. Proc R Soc Biol Sci B. doi:10.1098/rspb.2010.1953

Chen H, Smith GJD, Zhang SY, Qin K, Wang J, Li KS et al (2005) Avian flu: H5N1 virus outbreak in migratory waterfowl. Nature 436:191-192

Chiodini RJ, Vankruiningen HJ, Merkal RS (1984) Paratuberculosis (Johne's disease): The current status and future prospects. Cornell Vet 74:218-262

Corner LAL, Murphy D, Costello E, Gormley E (2009) Tuberculosis in European badgers (Meles meles) and the control of infection with Bacille Calmette-Guérin vaccination. J Wildl Dis 45:10421047 
Delahay RJ, Cheeseman CL, Clifton-Hadley RS (2001) Wildlife disease reservoirs: the epidemiology of Mycobacterium bovis infection in the European badger (Meles meles) and other British mammals. Tuberculosis 81:43-49

Delahay RJ, Smith GC, Hutchings MR (2009) The science of wildlife disease management. In: Delahay R, Smith G, Hutchings M (eds) Management of disease in wild mammals. Springer, New York, pp 1-8

Dolan LA (1993) Badgers and bovine tuberculosis in Ireland: A review. In: Hayden TH (ed) The badger. Royal Irish Academy, Dublin, pp 108-116

Donnelly CA, Hone J (2010) Is there an association between levels of bovine tuberculosis in cattle herds and badgers? Stat Comm Infect Dis 2:3

European Food Safety Authority (EFSA) (2010) Technical specifications for monitoring community trends in zoonotic agents in foodstuffs and animal populations on request from EFSA. EFSA J 8:1530-1545, Available online: www.efsa.europa.eu. Accessed June 2010

Fernández-de-Mera IG, Vicente J, Höfle U, Fons FR, Ortiz JA, Gortazar C (2009) Factors affecting red deer skin test responsiveness to bovine and avian tuberculin and to phytohaemagglutinin. Prev Vet Med 90:119-126

Garrido F, León-Vizcaíno L (1979) Diagnóstico de paratuberculosis caprina en Andalucía. In: Proceedings of the VII Congreso Nacional de Microbiología. SEM, Cádiz, p 321

Gortazar C, Vicente J, Samper S, Garrido JM, Fernandez-de-Mera IG, Gavin P et al (2005) Molecular characterization of Mycobacterium tuberculosis complex isolates from wild ungulates in southcentral Spain. Vet Res 36:43-52. doi:10.1051/vetres:2004051

Gortazar C, Acevedo P, Ruiz-Fons F, Vicente J (2006) Disease risks and overabundance of game species. Eur J Wildl Res 52:81-87

Gortazar C, Ferroglio E, Hofle U, Frolich K, Vicente J (2007) Diseases shared between wildlife and livestock: a European perspective. Eur J Wildl Res 53:241-256

Gortazar C, Torres J, Vicente J, Acevedo P, Reglero M, de la Fuente J et al (2008) bovine tuberculosis in Doñana biosphere reserve: the role of wild ungulates as disease reservoirs in the last Iberian lynx strongholds. PLoS ONE 3:e2776

Gortazar C, Vicente J, Boadella M, Ballesteros C, Galindo RC, Garrido $\mathrm{J}$ et al (in press) Progress in the control of bovine tuberculosis in Spanish wildlife. Vet Microbiol. doi:10.1016/j. vetmic.2011.02.041

Gortazar C, Delahay R, McDonald R, Boadella M, Wilson G, GavierWiden $\mathrm{D}$ et al (accepted for publication) The status of tuberculosis in European wildlife. Mammal Rev

Jewell NP (2009) Statistics for epidemiology. Chapman \& Hall/CRC, Washington

Joly DO, Samuel MD, Langenberg JA, Rolley RE, Keane DP (2009) Surveillance to detect chronic wasting disease in white-tailed deer in Wisconsin. J Wildl Dis 45:989-997

King AA, Fooks AR, Aubert M, Wandeler AI (2004) Historical perspective of rabies in Europe and the Mediterranean Basin. World Organization for Animal Health (OIE), Paris

Kock R, Kebkiba B, Heinonen R, Bedane B (2002) Wildlife and pastoral society - Shifting paradigms in disease control. Domestic Animal/Wildlife Interface: Issue for Disease Control, Conservation, Sustainable Food Production, and Emerging Diseases 969:24-33

Krebs JR (1997) Bovine tuberculosis in cattle and badgers. Ministry of Agriculture, Fisheries and Food, London, p 191

Leighton A (1995) Surveillance of wild animal diseases in Europe. Rev Sci Tech 14:819-830

López G, López-Parra M, Fernández L, Martínez-Granados C, Martínez F et al (2009) Management measures to control a feline leukemia virus outbreak in the endangered Iberian lynx. Anim Conserv 12:173-182

Maio E, Carta T, Balseiro A, Sevilla IA, Romano A, Ortiz JA et al (in press) Paratuberculosis in European wild rabbits from the Iberian Peninsula. Res Vet Sci. doi:10.1016/j.rvsc.2010.12.014

Martín-Atance P, Palomares F, González-Candela M, Revilla E, Cubero MJ, Calzada J, León-Vizcaíno L (2005) Bovine tuberculosis in a free ranging red fox (Vulpes vulpes) from Doñana National Park (Spain). J Wildl Dis 41:435-436

Martín-Hernando MP, Hofle U, Vicente J, Ruiz-Fons F, Vidal D, Barral M et al (2007) Lesions associated with Mycobacterium tuberculosis complex infection in the European wild boar. Tuberculosis 87:360-367

Martín-Hernando MP, Torres MJ, Aznar J, Negro JJ, Gandía A, Gortazar C (2010) Distribution of lesions in red and fallow deer naturally infected with Mycobacterium bovis. J Comp Pathol 142:43-50

McDonald RA, Delahay RJ, Carter SP, Smith GC, Cheeseman CL (2008) Perturbing implications of wildlife ecology for disease control. Trends Ecol Evol 23:53-56

Millán J, Candela MG, Palomares F, Cubero MJ, Rodríguez A, Barral $M$ et al (2009) Disease threats to the endangered Iberian lynx (Lynx pardinus). Vet J 182:114-124

Mörner T, Obendorf D, Artois M, Woodford M (2002) Surveillance and monitoring of wildlife diseases. Rev Sci Tech $21: 67-76$

Müller T, Teuffert J, Ziedler K, Possardt C, Kramer M, Staubach C et al (1998) Pseudorabies in the European wild boar from Eastern Germany. J Wildl Dis 34:251-258

Muñoz P, Boadella M, Arnal M, de Miguel M, Revilla M, Martinez D et al (2010) Spatial distribution and risk factors of Brucellosis in Iberian wild ungulates. BMC Infect Dis 10:46

Naranjo V, Gortazar C, Vicente J, de la Fuente J (2008) Evidence of the role of European wild boar as a reservoir of Mycobacterium tuberculosis complex. Vet Micro 127:1-9

Naser SA, Ghobrial G, Romero C, Valentine JF (2004) Culture of Mycobacterium avium subspecies paratuberculosis from the blood of patients with Crohn's disease. Lancet 364:1039-1044

Oleaga A, Casais R, Gonzalez-Quiros P, Prieto M, Gortazar C (2008) Sarcoptic mange in red deer from Spain: Improved surveillance or disease emergence? Vet Parasitol 154:103-113

Palmer MV (2007) Tuberculosis: A reemerging disease at the interface of domestic animals and wildlife. Curr Top Microbiol Immunol 315:195-215

Peña L, Garcia P, Jiménez MA, Benito A, Alenza MDP, Sánchez B (2006) Histopathological and immunohistochemical findings in lymphoid tissues of the endangered Iberian lynx (Lynx pardinus). Comp Immunol Microbiol Infect Dis 29:114-126

Pfeiffer DU, Robinson TP, Stevenson M, Stevens KB, Rogers DJ, Clements ACA (2008) Spatial analysis in epidemiology. Oxford University Press, New York

Reyes-García R, Perez-de-la-Lastra JM, Vicente J, Ruiz-Fons F, Garrido JM, Gortazar C (2008) Large-scale ELISA testing of Spanish red deer for paratuberculosis. Vet Immunol Immunopathol 124:75-81

Rhyan JC, Spraker TR (2010) Emergence of diseases from wildlife reservoirs. Vet Pathol 47:34-39

Rodríguez-Sánchez B, Gortazar C, Ruiz-Fons F, Sánchez-Vizcaíno JM (2010) Bluetongue virus serotypes 1 and 4 in red deer, Spain. Emerg Infect Dis 16:518-520

Rossi S, Artois M, Pontier D, Cruciere C, Hars J, Barrat J et al (2005) Long-term monitoring of Classical swine fever in wild boar (Sus scrofa sp.) using serological data. Vet Res 36:27-42

Ruiz-Fons F, Reyes-Garcia AR, Alcaide V, Gortazar C (2008) Spatial and temporal evolution of bluetongue virus in wild ruminants, Spain. Emerg Infect Dis 14:951-953 
Santos N, Correla-Neves M, Ghebremichael S, Källenius G, Svenson SB, Almeida V (2009) Epidemiology of Mycobacterium bovis infection in wild boar (Sus scrofa) from Portugal. J Wildl Dis 45:1048-1061

Santos N, Geraldes M, Afonso A, Almeida V, Correia-Neves M (2010) Diagnosis of Tuberculosis in the Wild Boar (Sus scrofa): A Comparison of Methods Applicable to Hunter-Harvested Animals. PLoS ONE 5. doi:10.1371/journal.pone.0012663

Sobrino R, Martín-Hernando MP, Vicente J, Gortazar C, Aurtenetxe O, Garrido JM (2008) Bovine tuberculosis in a badger (Meles meles) in Spain. Vet Rec 163:159-160

Sobrino R, Acevedo P, Escudero MA, Marco J, Gortazar C (2009) Carnivore population trends in Spanish agrosystems after the reduction in food availability due to rabbit decline by rabbit haemorrhagic disease and improved waste management. Eur J Wildl Res 55:161-165

Sobrino R, Aurtenetxe O, Carta T, Mamian L, Gerrikagoitia X, Balseiro A et al (2011) Lack of evidence of paratuberculosis in wild canids from south-western Europe. Eur J Wildl Res 57:683688

Tayce J, Acevedo P, Vicente J, Gortazar C (2008) Minimum sampling effort for reliable non-invasive estimations of excretion abundance of Elaphostrongylus cervi L1 in red deer (Cervus elaphus) populations. J Helminthol 82:255-261

Tompkins DM, Ramsey DSL, Cross ML, Aldwell FE, De Lisle GW, Buddle BM (2009) Oral vaccination reduces the incidence of tuberculosis in free-living brushtail possums. Proc R Soc Biol Sci B 276:2987-2995
Uzoigwe JC, Khaitsa ML, Gibbs PS (2007) Epidemiological evidence for Mycobacterium avium subspecies paratuberculosis as a cause of Crohn's disease. Epidemiol Infect 135:1057-1068

Vicente J, Hofle U, Garrido JM, Fernandez-de-Mera IG, Juste R, Barral $\mathrm{M}$ et al (2006) Wild boar and red deer display high prevalences of tuberculosis-like lesions in Spain. Vet Res 37:107-119

Vicente J, Hofle U, Garrido JM, Fernandez-de-Mera IG, Acevedo P, Juste R et al (2007) Risk factors associated with the prevalence of tuberculosis-like lesions in fenced wild boar and red deer in south central Spain. Vet Res 38:451-464

Villafuerte R, Calvete C, Gortazar C, Moreno S (1994) First epizootic of rabbit hemorrhagic disease in free-living populations of Oryctolagus cuniculus at Doñana National Park, Spain. J Wildl Dis 30:176-179

Wacker K, Rodriguez E, Garate T, Geue L, Tackmann K, Selhorst T, Staubach C, Conraths FJ (1999) Epidemiological analysis of Trichinella spiralis infections of foxes in Brandenburg, Germany. Epidemiol Infect 123:139-147

Wobeser G (1994) Investigation and management of disease in wild animals. Springer, New York

Woodford MH (2009) Veterinary aspects of ecological monitoring: The natural history of emerging infectious diseases of humans, domestic animals and wildlife. Trop Anim Health Prod 41:1023-1033

Wyss D, Giacometti M, Nicolet J, Burnens A, Pfyffer GE, Audige L (2000) Farm and slaughter survey of bovine tuberculosis in captive deer in Switzerland. Vet Rec 147:713-717

Zuur AF, Ieno EN, Walker NJ, Saveliev AA, Smith GM (2009) Mixed effects models and extensions in ecology with R. Springer, New York 